\title{
Carsten Sprenger
}

\section{Internationale Expertenhaftung}

Die Dritthaftung von Experten im Internationalen Privat- und Zivilverfahrensrecht

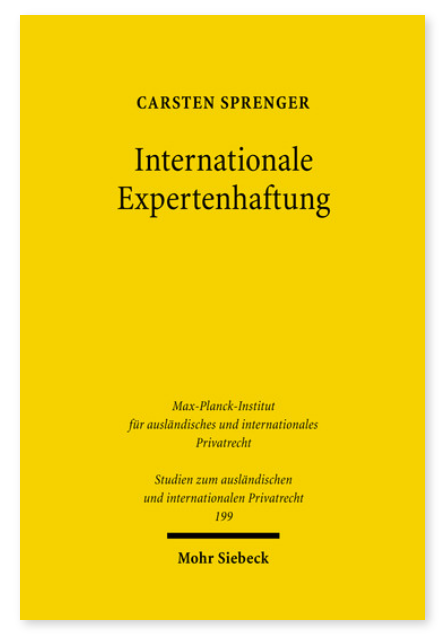

2008. XVIII, 306 Seiten. StudIPR 199

ISBN 978-3-16-151384-8

DOI 10.1628/978-3-16-151384-8

eBook PDF 79,00€

ISBN 978-3-16-149654-7

fadengeheftete Broschur 79,00€
Bereits im materiellen Recht verursacht die Haftung für Vermögensschäden, die durch fehlerhafte Gutachten von Experten und Sachverständigen entstehen, zahlreiche Schwierigkeiten. Wenn es zu grenzüberschreitenden Haftungsfällen von Experten gegenüber Dritten kommt, stellt sich zusätzlich die Frage nach dem anwendbaren Recht und dem international zuständigen Gericht. Auch insoweit wird deutlich, dass sich die Expertenhaftung im Zwischenbereich von vertraglicher und deliktischer Haftung abspielt. Auf der Grundlage eines Vergleichs des deutschen, englischen und französischen Sachrechts untersucht Carsten Sprenger die kollisions- und internationalverfahrensrechtlichen Grundfragen der Expertenhaftung. Im Mittelpunkt steht die Qualifikation der Expertenhaftung als vertragliche oder deliktische Haftung, für die neben materiellrechtlich geprägten Kriterien vor allem die kollisionsrechtlichen Interessen der beteiligten Personen entscheidend sind. Maßgebende Topoi sind der äußere und innere Entscheidungseinklang, die Verhaltenssteuerung durch Haftungsrisiken, die Verteilung der Informations- und Transaktionskosten sowie die Einbettung der Gutachterleistung in einen Leistungsverbund. Im Ergebnis befürwortet der Autor eine vertragsähnliche Qualifikation, für die auf der Ebene der Anknüpfung zahlreiche Folgefragen (wie etwa die Möglichkeit einer Rechtswahl im Gutachten) behandelt werden. Im Rahmen der Internationalen Zuständigkeit erörtert er den Gerichtsstand am Erfüllungs- und am Erfolgsort sowie die Einräumung eines zusätzlichen Gerichtsstandes im Gutachten.

Carsten Sprenger Geboren 1979; Studium der Rechtswissenschaft in Münster und Paris (Maîtrise en Droit); 2007 Promotion; seit 2007 Referendariat in Hamburg und Brüssel.

Jetzt bestellen:

https://mohrsiebeck.com/buch/internationale-expertenhaftung-9783161513848?no_cache=1

order@mohrsiebeck.com

Telefon: $+49(0) 7071-923-17$

Telefax: $+49(0) 7071-51104$ 